\title{
Anatomia e ultra-estrutura foliar de Cyperus maritimus Poir. (Cyperaceae): estratégias adaptativas ao ambiente de dunas litorâneas ${ }^{1}$
}

\author{
Shirley Martins ${ }^{2,4}$, Silvia Rodrigues Machado ${ }^{3}$ e Marccus Alves²
}

Recebido em 14/02/2007. Aceito em 10/07/2007

\begin{abstract}
RESUMO - (Anatomia e ultra-estrutura foliar de Cyperus maritimus Poir. (Cyperaceae): estratégias adaptativas ao ambiente de dunas litorâneas). Foram analisados aspectos anatômicos e ultra-estruturais foliares de Cyperus maritimus Poir. visando identificar caracteres adaptativos ao ambiente de dunas litorâneas. Para isto, indivíduos ocorrentes nas dunas da Praia de Pipa, Rio Grande do Norte, Brasil, tiveram as folhas submetidas a diferentes análises: microscopia de luz, eletrônica de varredura e de transmissão. Em vista frontal, a epiderme possui tricomas unicelulares, corpos de sílica, cutícula estriada e depósitos de cera. Em secção transversal, a epiderme é unisseriada com parede periclinal externa espessa. Os estômatos são paracíticos, podendo o ostíolo estar obstruído por cera. Abaixo da face adaxial observa-se o parênquima aqüífero. Os feixes vasculares ocorrem em múltiplas fileiras, sendo as periféricas compostas por feixes de diâmetro menor que os feixes da fileira central. Foram observados caracteres relacionados à síndrome Kranz do tipo clorociperóide. Aspectos ultra-estruturais, como cloroplastos presentes na bainha do feixe, esses sem grana evidentes, entre outras características, reforçam a possível ocorrência da via $\mathrm{C}_{4}$ nesta espécie. É a primeira citação para o gênero Cyperus de cloroplasto nas celulas do tecido vascular. Neste trabalho foi possível observar vários caracteres importantes para plantas submetidas a estresse hídrico e salino, como: cera, células epidérmicas com parede periclinal externa espessada, parênquima aqüífero e síndrome Kranz.
\end{abstract}

Palavras-chave: Cyperus, Kranz, anatomia, ultra-estrutura, salinidade

\begin{abstract}
Leaf anatomy and ultrastructure of Cyperus maritimus Poir. (Cyperaceae): adaptive strategies for coastal dune environment). Anatomical and ultrastructural aspects of Cyperus maritimus Poir. were analyzed with the aim of identifying adaptive features for the dune environment. Collections were made at Pipa beach, Rio Grande do Norte, Brazil. Leaves were submitted to different analyses: light microscopy, scanning and transmission electron microscopy. In frontal view, the epidermis has unicellular trichomes, silica bodies, a striate cuticle and wax deposits. In transverse section, the epidermis is uniseriate with thickened outer periclinal walls. The stomata are paracitic and the pore sometimes obstructed by wax. Under the adaxial epidermis, there are several layers of aqueous parenchyma. The vascular bundles occur in multiple rows, the peripheral row having bundles with narrower diameters than the central row. Characters related to Kranz syndrome of the chlorocyperoid type were observed. Ultrastructural features support a possible $\mathrm{C}_{4}$ pathway in this species. This work is the first citation of chloroplasts in the cells of the vascular system for the genus. In this study, it was possible to observe several important features of plants submitted to water and salt stress, such as: wax, thickened outer periclinal walls of the epidermal cells, aqueous parenchyma and Kranz syndrome.
\end{abstract}

Key words: Cyperus, Kranz, anatomy, ultrastructure, salinity

\section{Introdução}

As comunidades vegetais ocorrentes em dunas litorâneas são caracterizadas por tolerarem altos níveis de salinidade, deficiência hídrica e de nutrientes, ampla variação de umidade e temperatura, além de injúrias causadas pelos fortes ventos (Maun 1994).

Entre os prejuízos causados às plantas submetidas à alta sanilidade estão: a redução do crescimento, a inibição da divisão e expansão celular, a desorganização celular, o acúmulo de metabólitos tóxicos, a inibição da fotossíntese e a diminuição na aquisição de nutrientes (Flowers et al. 1985; Hasegawa \& Bressan 2000). Os fatores que atuam na tolerância a esses altos níveis de salinidade são freqüentemente dependentes da complexidade anatômica e fisiológica da planta (Shannon 1997).

A maioria dos trabalhos referentes à resistência à salinidade trata dos aspectos fisiológicos das plantas (Flowers et al. 1977; Prisco 1980; Flowers \& Yeo 1986;

\footnotetext{
1 Parte da Dissertação de Mestrado da primeira Autora

2 Universidade Federal de Pernambuco, Centro de Ciências Biológicas, Departamento de Botânica, Av. Prof. Moraes Rego s.n., Cidade Universitária, 50670-901 Recife, PE, Brasil

3 Universidade Estadual de São Paulo, Instituto de Biociências, Departamento de Botânica, C. Postal 510, 18618-000 Botucatu, SP, Brasil

4 Autor para correspondência: shirley_botany@yahoo.com.br
} 
Marcum \& Murdoch 1992), entretanto, poucos estudos abordam as adaptações morfológicas apresentadas por estas. Dentre esses estudos, temos os referentes a aspectos gerais de adaptações em diferentes grupos vegetais (Yeo 1983; Fahn \& Cutler 1992).

Além da escassez de informações sobre estratégias adaptativas, a ênfase maior dos trabalhos sobre salinidade é destinada a plantas de interesse econômico, como, por exemplo, os trabalhos com Oriza sativa L. (Flowers et al. 1985), Solanum lycopersicum L. (Sam et al. 2003) e Triticum aestivum L. (Hu et al. 2005). Sobre as espécies nativas ocorrentes em dunas litorâneas pouco é conhecido, onde se destacam os trabalhos realizados com espécies de Poaceae, principalmente do gênero Spartina (Levering \& Thomson 1971; Perazzolo \& Pinheiro 1991; Rozema et al. 1991; Naidoo et al. 1992), Sporobolus virginicus (L.) Kunth (Marcum \& Murdoch 1992) e Triplasis purpurea (Walt) Chapm (Cheplick \& White 2002), além de Scirpus maritimus L. e Puccinellia maritima (Huds.) Parl. (Rozema et al. 1991).

As plantas ocorrentes em dunas estão submetidas não só ao estresse salino, mas também ao estresse hídrico. Entre as estratégias anatômicas ressaltadas como importantes para plantas de dunas litorâneas submetidas as esses estresses é destacada a presença de cera epicuticular, resinas, cutícula espessa, glândulas de sal e parênquima aqüífero bem desenvolvido (Flowers et al. 1977; Perazzolo \& Pinheiro 1991; Fahn \& Cutler 1992; Jordaan \& Kruger 1992; Naidoo et al. 1992; Shannon 1997). Os aspectos ultra-estruturais, principalmente relacionados a morfologia dos cloroplastos, são também considerados relevantes em estudos sobre o efeito do estresse salino (Flowers et al. 1985; Dekov et al. 2000).

Atualmente, o ambiente dunal tem despertado interesse científico por abrigar espécies endêmicas (FEEMA 1988) e pelo relevante papel ecológico desempenhado pelas espécies na preservação da morfologia costeira (Cordazzo \& Seelinger 2003; Cordeiro 2005). Entre os representantes da vegetação costeira no Brasil, espécies das famílias Poaceae e Cyperaceae são consideradas de grande importância nesse ambiente, por atuarem na rápida colonização das dunas e na fixação do sedimento, reduzindo assim os danos causados pela erosão (Matias \& Nunes 2001; Cordeiro 2005).

Cyperaceae é uma das famílias mais representativas nesses ambientes (Luceño et al. 1997; Goetghebeur 1998; Matias \& Nunes 2001; Cordeiro 2005). Remirea maritima Aubl. e Cyperus maritimus
Poir. são exemplos de espécies dessa família que ocorrem no Brasil e têm distribuição restrita às dunas litorâneas (Luceño et al. 1997). Remirea maritima já foi descrita do ponto de vista estrutural e ultra-estrutural por Oteng-Yeboah (1975) e Estelita (1992, 1993), porém sem explorar as possíveis estratégias adaptativas dessa espécie.

No Brasil, C. maritimus teve sua presença registrada em dunas litorâneas dos estados da Bahia, Ceará, Paraiba e Rio Grande do Norte (Luceño et al. 1997; Cordeiro 2005), sendo sua presença indicativa de áreas pouco antropizadas (Luceño et al. 1997). Pertence, juntamente a outras 24 espécies, à Cyperus sec. Arenarii (Väre \& Kukkonen 2005). Os taxóns dessa seção apresentam uma forte relação com ambientes dunais, sendo a maioria das espécies psamófila (plantas que vivem em zonas arenosas) e ocorre em dunas costeiras e desertos (Väre \& Kukkonen 2005).

Diante das poucas informações sobre os aspectos estruturais das plantas ocorrentes em dunas, principalmente de espécies da Cyperaceae, e sendo C. maritimus uma espécie atualmente vulnerável à ação antrópica, é objetivo deste trabalho descrever estruturalmente as folhas desta espécie, visando identificar caracteres indicativos de adaptações ao ambiente de dunas litorâneas.

\section{Material e métodos}

Material botânico - Indivíduos de Cyperus maritimus foram coletados em fevereiro/2004 e maio/2006, nas dunas da Praia de Pipa, município de Tibau do Sul RN (35\%03'05" e 6 03'40") - S. Martins et al. 49 e S. Martins \& M. Alves 226, sendo parte herborizada e depositada no Herbário UFP da Universidade Federal de Pernambuco (UFPE) e parte processada para análises anatômicas e ultra-estruturais.

Microscopia de luz (ML) - Para observação da epiderme em vista frontal, fragmentos foliares foram fervidos em solução de ácido nítrico a 50\% (Ghouse \& Yunus 1972) até a dissociação. Posteriormente, o material foi lavado em água destilada, corado com safranina 50\% (Kraus \& Arduin 1997) e montado em lâminas semi-permanentes em glicerina 50\%. Para a descrição anatômica do limbo foliar, foram realizadas secções transversais (ST) a mão livre, com o auxílio de lâmina de barbear, da região mediana do limbo de folhas totalmente expandidas de seis amostras no total, sendo três de cada período de coleta. Estas foram 
clarificadas com hipoclorito de sódio 50\%, coradas com azul de Astra e safranina (Kraus \& Arduin 1997) e montadas em glicerina 50\% (Purvis et al. 1964). As ST foram também submetidas a testes microquímicos com Lugol (Berlyn \& Miksche 1976) para identificação de amido; cloreto férrico (Johansen 1940) para substâncias fenólicas e Sudan IV (Sass 1951) para lipídios. O material foi analisado usando o fotomicroscópio Zeiss MC 80.

Microscopia eletrônica de varredura (MEV) Amostras da região mediana de folhas totalmente expandidas, foram fixadas em glutaraldeído $2,5 \% \mathrm{em}$ tampão fosfato $0,1 \mathrm{M}, \mathrm{pH}$ 7,3, pós-fixadas em tetróxido de ósmio a 0,5\%, lavadas em água destilada, desidratadas em série etílica, secadas em "ponto crítico" utilizando carbono líquido e metalizadas em ouro. A observação foi realizada em microcoscópio eletrônico de varredura Phillips SEM 515, 20 kV.

Microscopia eletrônica de transmissão (MET) Amostras da região mediana de folhas totalmente expandidas foram fixadas em glutaraldeído $2,5 \% \mathrm{em}$ tampão fosfato $0,1 \mathrm{M}, \mathrm{pH} 7,3$, pós-fixadas em tetróxido de ósmio a $0,5 \%$, lavadas em água destilada, desidratadas em série crescente de soluções de acetona, embebidas e incluídas em Araldite. Os cortes ultra-finos foram constratados com citrato de chumbo e acetato de uranila etílica e visualizados em microscópio eletrônico de transmissão Phillips EM 100, 80 kV.

\section{Resultados}

Cyperus maritimus é uma herbácea perene com cerca de $30 \mathrm{~cm}$ alt. que ocorre em dunas litorâneas, formando grandes touceiras. Apresenta rizoma bem desenvolvido e as folhas dispostas em roseta, sendo canaliculadas, lanceoladas, com margens escabras, ápice longo-atenuado e bainha aberta (Fig. 1). As folhas apresentam um aspecto glaucescente devido ao depósito de cera.

Em MEV, o limbo foliar apresenta tricomas unicelulares curtos (Fig. 2), com parede espessa e silicificada, distribuídos apenas na face adaxial, ao longo das nervuras de maior calibre e na margem foliar. A cutícula apresenta estrias dispostas longitudinalmente em ambas as faces, sendo mais conspícuas na face abaxial. Depósitos amorfos de cera ocorrem em ambas as faces epidérmicas, entretanto, são mais evidentes na adaxial (Fig. 3). Em ambas as faces epidérmicas, a maioria das células é retangular com paredes anticlinais retas na face adaxial e levemente sinuosas na abaxial
(Fig. 3-4). Entre essas células epidérmicas retangulares ocorrem fileiras uni a bisseriadas de células estreitas com paredes anticlinais sinuosas, essas apresentando 2-4 corpos de sílica por célula com formato circular (Fig. 4). Os corpos de sílica são restritos à essas células estreitas, que se localizam em ambas as faces, porém, principalmente na abaxial. Os estômatos são paracíticos, restritos à face abaxial e distribuídos em fileiras longitudinais ao longo da zona intercostal (Fig. 4).

Em ML, a folha possui epiderme unisseriada (Fig. 5). Metcalfe (1971) classifica a epiderme em espécies de Cyperaceae em duas categorias com relação ao tamanho das células epidérmicas nas faces abaxial e adaxial. Na primeira categoria as células das diferentes faces apresentam proporções diferentes, onde é possível observar, de acordo com as ilustrações, que o tamanho das células de uma das faces é três ou mais vezes maior que as células da outra face. Portanto, em geral as células da face adaxial são maiores que as da abaxial. Na segunda categoria, as células das diferentes faces apresentam proporções semelhantes, ou seja, a diferença entre elas não ultrapassa a medida proposta para a situacao anterior. Com base no exposto, em C. maritimus as células das diferentes faces apresentam proporções semelhantes.

Ainda referente a epiderme, temos que em C. maritimus a cutícula é delgada e a parede periclinal externa das células epidérmicas é espessa em ambas as faces (Fig. 6, 8). Os corpos de sílica são cônicos, ocorrendo no interior das células epidérmicas, fixados à parede periclinal interna (Fig. 6, 8). As células portadoras dos corpos silicosos estão sempre associadas aos cordões de fibras (Fig. 6, 8) e são as mesmas que em vista frontal se dispõem em fileiras uni a bisseriadas. A face epidérmica adaxial apresenta leves sulcos, onde se localizam os cordões de fibras, conferindo um aspecto ondulado a esta face (Fig. 5-6). Internamente à face adaxial observa-se uma fileira descontínua de células parenquimáticas com paredes delgadas e maiores que as células epidérmicas, semelhante à células buliforme (Fig. 6). Abaixo destas células, ocorrem 3-5 camadas de células parenquimáticas isodiamétricas grandes com paredes delgadas e aspecto translúcido, constituindo o parênquima aqüífero (Fig. 5-6).

Os estômatos ocorrem no mesmo nível das demais células epidérmicas, com a parede das células-guarda fortemente espessada (Fig. 7). Alguns estômatos apresentam o ostíolo obstruído por depósitos de cera (Fig. 7). A câmara subestomática é reduzida, sendo 
delimitada por duas células parenquimáticas alongadas e estreitas (Fig. 8).

Os feixes vasculares são do tipo colateral, localizados próximos à face abaxial e dispostos em duas a três fileiras (Fig. 5). A fileira mais interna é formada por feixes de maior calibre e as mais periféricas por de menor calibre, porém com tamanhos diferentes. Nas fileiras periféricas, os feixes (de pequeno calibre) estão localizados próximos entre si e apresentam duas bainhas, a externa com células de parede fortemente espesssada (bainha mestoma) e a interna com células maiores e parede menos espessa (bainha Kranz) (Fig. 8-9). Na fileira mais interna, os feixes (de maior calibre) apresentam os elementos do metaxilema interrompendo a bainha Kranz (Fig. 9). Ainda nesses feixes, além das bainhas Kranz e
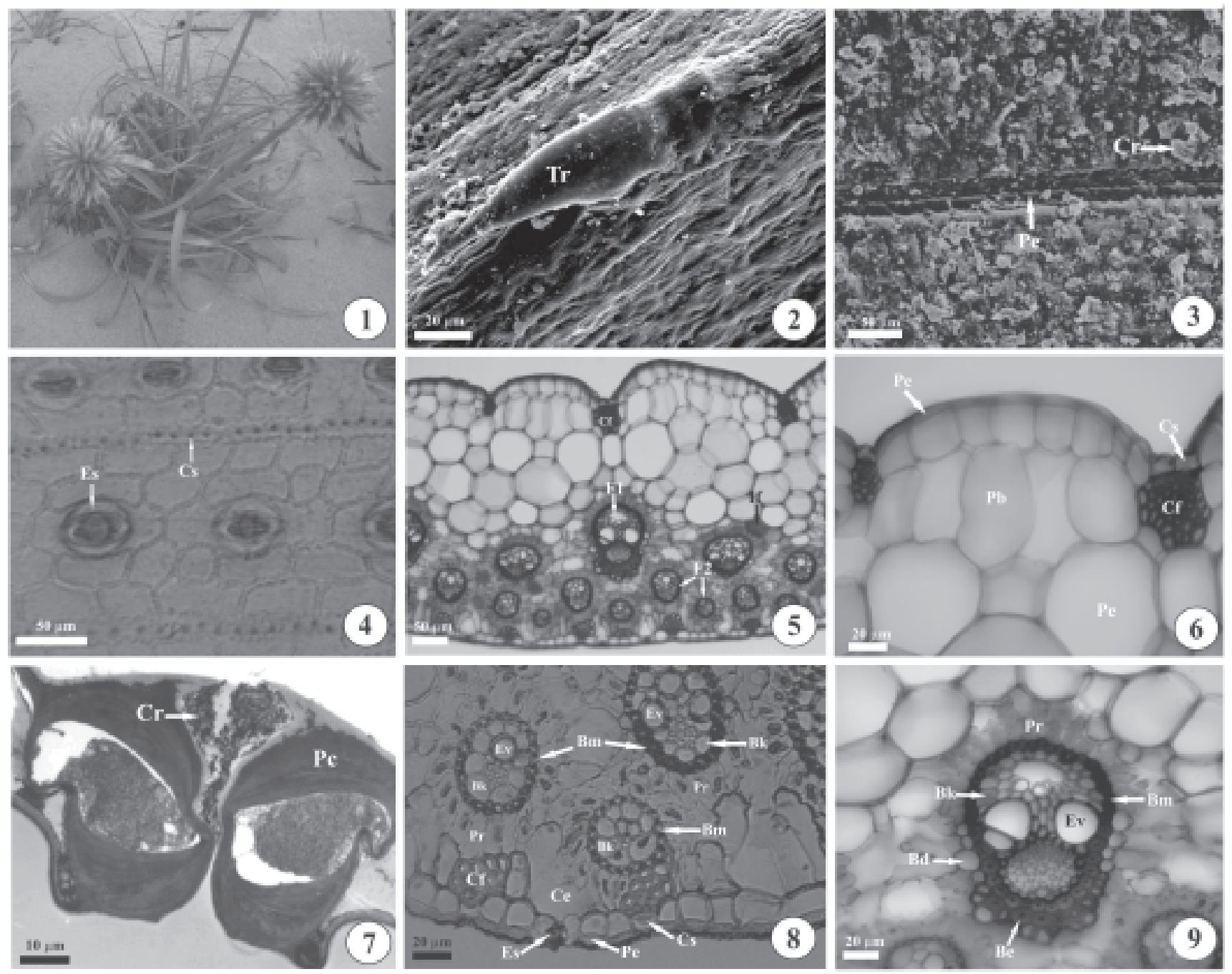

Figuras 1-9. Cyperus maritimus Poir. 1. Hábito. 2-9. Folhas. 2-3. Face adaxial em MEV. 2. Epiderme com tricoma unicelular. 3. Células da epiderme com depósitos de cera. 4. Vista frontal em ML da face abaxial com estômatos paracíticos e células com corpos de sílica. 5. Visão geral em ST, destacando o aspecto ondulado da lâmina foliar, o parênquima aqüífero e os feixes vasculares dispostos em duas a três fileiras. 6. Detalhe da face adaxial destacando a parede periclinal externa espessa, os corpos de sílica, os sulcos, os cordões de fibras, o parênquima com aspecto buliforme e o parênquima aqüífero. 7. Estômato em MET com parede das células-guarda espessa e cera no ostíolo. 8-9. Folha em ST. 8. Detalhe da região abaxial mostrando: epiderme com parede periclinal externa espessa, cordões de fibras, corpo de sílica cônico, câmara subestomática e feixes de menor calibre com estrutura Kranz. 9. Feixe de maior calibre mostrando parênquima radiado interrompido pela terceira bainha, formada por células com parede delgada e espessa, a bainha mestoma e a bainha Kranz interrompida pelo elementos do metaxilema. $(\mathrm{Bd}=$ bainha com células de parede delgada; $\mathrm{Be}=$ bainha com células de parede espessa; $\mathrm{Bk}=$ bainha Kranz; $\mathrm{Bm}$ = bainha mestoma; $\mathrm{Cf}=$ cordão de fibras; $\mathrm{Ce}=$ câmara subestomática; $\mathrm{Cr}=$ cera; $\mathrm{Cs}=\mathrm{corpos}$ de sílica; $\mathrm{Ce}$ = câmara subestomática; Es = estômato; Ev = elemento de vaso; F1 = feixes de maior calibre; F2 = feixes de menor calibre; If = idioblasto fenólico; $\mathrm{Pa}=$ parênquima aquífero; $\mathrm{Pb}=$ parênquima com aspecto buliforme; $\mathrm{Pc}=$ parede da célula-guarda; $\mathrm{Pe}=$ parede periclinal externa; $\operatorname{Pr}=$ parênquima radiado; $\operatorname{Tr}=$ tricoma). 
mestoma, ocorre uma terceira bainha incompleta, envolvendo metade do feixe, principalmente na região adjacente ao floema (Fig. 9). Essa terceira bainha apresenta algumas células com parede espessa, localizadas abaxialmente, e outras com parede delgada dispostas na lateral do feixe (Fig. 9).

O parênquima clorofiliano apresenta disposição radiada em torno dos feixes vasculares, envolvendo completamente aqueles de menor calibre, localizados na fileira periférica (Fig. 8). Nos feixes de maior calibre, esse tecido envolve apenas a metade do feixe, sendo interrompido pela terceira bainha parenquimática (Fig. 9).

$\mathrm{Na}$ análise de MET dos tecidos fotossintéticos, as células do parênquima radiado apresentam 2-3 cloroplastos elipsóides, localizados próximos à parede celular (Fig. 10), cujo sistema lamelar apresenta grana bem desenvolvido e retículo periférico inconspícuo (Fig. 11). Plastoglóbulos são visualizados no interior desses cloroplastos (Fig. 11). Plasmodesmos são observados entre as células do parênquima radiado e entre essas células e a bainha mestoma. Na terceira bainha que envolve o feixe, as células com parede delgada, localizadas lateralmente ao feixe, apresentam pequenos cloroplastos com grana evidentes, situados próximos à parede das células (Fig. 12).

Na bainha mestoma, os cloroplastos estão ausentes e as células apresentam lúmen reduzido com parede fortemente espessada e polilamelada (Fig. 12-13). A presença de lamela de suberina é também evidenciada (Fig. 13).

As células da bainha Kranz apresentam 2-5 cloroplastos volumosos, com formato arredondado a amebóide, geralmente ocupando mais da metade da célula e localizados em posição centrípeta (Fig. 14). Nos cloroplastos dessa bainha, o sistema lamelar é reduzido, sem grana desenvolvidos e formado por tilacóides convolutos (Fig. 15-16). Dentro dos cloroplastos são observados grãos de amido elipsóides e vários plastoglóbulos (Fig. 15-16). Substâncias fenólicas ocorrem no interior das células da bainha Kranz. Os plasmodesmos são observados entre as células Kranz, entre estas células e as da bainha mestoma, e também entre as células Kranz e as células do parênquima vascular (Fig. 13, 17).

Cloroplastos com formato alongado ocorrem também nas células do parênquima xilemático (Fig. 17). Contudo, esses diferem dos ocorrentes na bainha Kranz, por apresentarem grana pouco evidentes e menos estruturados que os presentes no parênquima radiado (Fig. 18).
Não foram observadas diferenças entre as células dos tecidos fotossintéticos quanto à presença e organização de outras organelas, tais como mitocôndrias e microcorpos.

\section{Discussão}

A disposição das folhas em roseta, como a apresentada por $C$. maritimus, é relatada como um mecanismo difundido entre as plantas submetidas à condições salinas visando a exclusão do sal, onde grandes quantidades de íons podem ficar acumulados nas folhas maduras e senescentes, sendo então liberados com a abscisão destas (Ashraf \& O'Leary 1997; Hasegawa \& Bressan 2000). A presença de folhas canaliculadas e glaucescentes, observadas em C. maritimus é também citada para a maioria das espécies de Cyperus sec. Arenarii como uma estratégia na redução da perda de água por evaporação (Väre \& Kokkonenn 2005).

As características do tecido epidérmico de C. maritimus, como, paredes celulares espessas e depósitos de cera epicuticulares, são consideradas de grande importância para plantas submetidas à déficit hídrico (Perazzolo \& Pinheiro 1991; Fahn \& Cutler 1992; Shannon 1997). Células epidérmicas com paredes espessas são indicadas como importantes na resistência mecânica contra desidratação e resistência à condições xéricas (Fahn \& Cutler 1992; Oliveira \& Sajo 1999). Com relação a cera epicuticular, sua presença reduz a perda excessiva de água durante a transpiração, pois, quando os estômatos estão fechados, esta perda é determinada pela taxa de transpiração cuticular, sendo a sobrevivência das plantas dependente quase que exclusivamente da permeabilidade da cutícula (Ihlenfeldt \& Hartmann 1982; Salatino et al. 1986). Desse modo, a presença dos depósitos de cera em C. maritimus pode atuar na redução da taxa de transpiração. A presença de corpos de sílica é também sugerida, como uma característica adaptativa que auxilia na redução da transpiração em folhas e no aumento da eficiência no uso da água (Prichid et al. 2004).

Com relação aos estômatos, sua restrição à face abaxial, como aqui observado, pode estar relacionada à proteção dos mesmos contra elevadas taxas de evaporação (Rozema 1991). Em plantas submetidas a estresse salino, o fechamento estomático é considerado a primeira linha de defesa contra o dessecamento (Chaves \& Oliveira 2004). Além da presença de depósitos de cera no interior do ostíolo e de célulasguarda com paredes espessas, como observado em 
498 Martins, Machado \& Alves: Anatomia e ultra-estrutura foliar de Cyperus maritimus Poir. (Cyperaceae): estratégias...
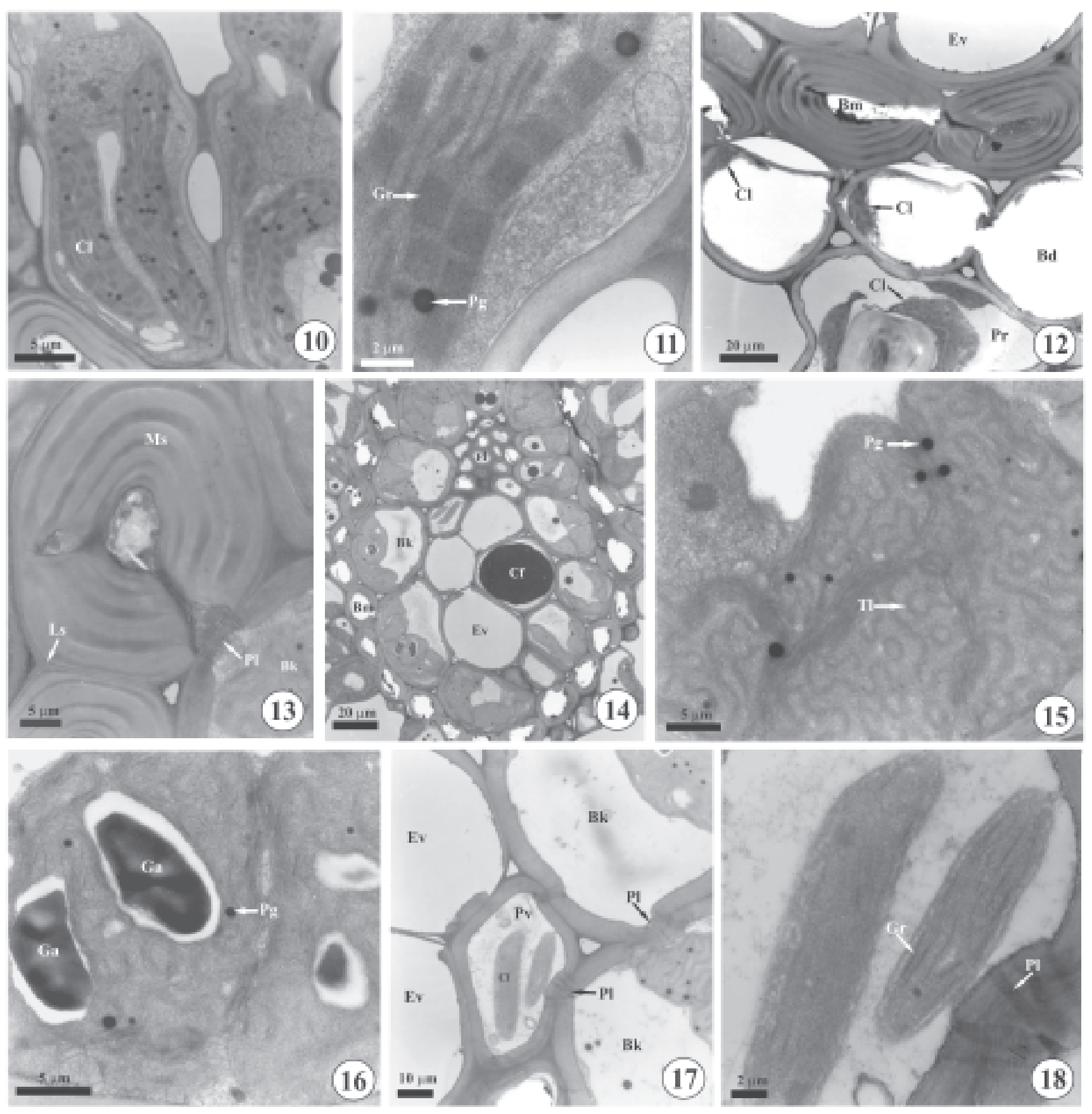

Figuras 10-18. Cyperus maritimus Poir. MET. 10. Células do parênquima radiado com cloroplastos alongados. 11. Detalhe dos cloroplastos com grana estruturado e plastoglóbulos. 12. Detalhe da bainha parequimática com células delgadas apresentando pequenos cloroplastos próximos à parede. 13. Detalhe de célula da bainha mestoma, mostrando a parede fortemente espessada e polilamelada, além da lamela de suberina e plasmodemos com a bainha Kranz. 14. Visão geral do feixe vascular, destacando o arranjo da bainha Kranz e compostos fenólicos no elemento de vaso. 15. Detalhe da célula Kranz com tilacóides convolutos e plastoglóbulos presentes nos cloroplastos. 16. Célula Kranz com grãos de amido elipsóides. 17. Destaca-se a presença de cloroplastos no parênquima xilemático, plasmodesmos entre a célula parenquimática e a bainha Kranz, e também entre as células da bainha Kranz. 18. Detalhe do parênquima vascular mostrando cloroplastos com grana e plasmodesmos. $(\mathrm{Bd}=$ bainha com células de parede delgada; Bk = bainha Kranz; Bm = bainha mestoma; $\mathrm{Cf}=$ compostos fenólicos; $\mathrm{Cl}=$ cloroplasto; $\mathrm{Ev}=$ elemento de vaso; $\mathrm{Fl}=$ floema; $\mathrm{Ga}=$ grãos de amido; $\mathrm{Gr}=$ grana; $\mathrm{Ls}=1 \mathrm{amela}$ de suberina; $\mathrm{Ms}=$ mestoma; $\mathrm{Pg}=$ plastoglóbulo $\mathrm{Pl}=$ plasmodesmos $; \mathrm{Pr}=$ parênquima radiado $; \mathrm{Pv}=$ parênquima vascular; $\mathrm{Tl}=$ tilacóide $)$. 
C. maritimus, a proteção estomática pode ser realizada pela oclusão do poro por resina, a presença de projeções cuticulares, papilas ou mesmo tricomas sobre o poro estomático, ou ainda pela localização dos estômatos em sulcos ou criptas (Perazzolo \& Pinheiro 1991; Fahn \& Cutler 1992; Oliveira \& Sajo 1999; Alvarez et al. 2005). Esses mecanismos que atuam na proteção estomática são comuns às plantas que se desenvolvem sob estresses salino e hídrico (Flowers et al. 1977; Fahn \& Cutler 1992; Jordaan \& Kruger 1992).

Entretanto, qualquer tipo de mecanismo que atue no fechamento estomático ou em sua obstrução implica em restrições na captação do $\mathrm{CO}_{2}$, o que não representaria um fator limitante nas espécies com via fotossintética $\mathrm{C}_{4}$ (Sage 2004). Entre as principais características anatômicas utilizadas para identificação de espécies com via $\mathrm{C}_{4}$ estão a presença do parênquima clorofiliano com disposição radiada, da bainha Kranz com cloroplastos abundantes e de feixes vasculares próximos entre si, separados por 3-4 células (Crookston 1980; Sage 2004). Essas características constituem conjuntamente a chamada "Síndrome Kranz".

Em Cyperaceae, as espécies com via fotossintética $\mathrm{C}_{4}$ são divididas em quatro tipos anatômicos, que são diferenciados pelo número de bainhas em torno dos feixes e pela continuidade, ou não, da bainha Kranz nos feixes de maior calibre, que neste último caso é interrompida pelos vasos do metaxilema (Soros \& Dengler 2001). No gênero Cyperus são encontradas ambas as vias fotossintéticas $\left(\mathrm{C}_{3}\right.$ e $\left.\mathrm{C}_{4}\right)$, sendo as espécios $\mathrm{C}_{4}$ do tipo clorociperóide. Este tipo se caracteriza pela presença de duas bainhas em torno dos feixes, sendo a mestoma externa à Kranz que é descontínua nos feixes de maior calibre (Soros \& Bruhl 2000). Em C. maritimus, além da presença das duas bainhas comuns ao tipo clorociperóide, ocorre nos feixes de maior calibre uma terceira bainha incompleta. $\mathrm{O}$ padrão comum observado nas demais espécies $\mathrm{C}_{4}$ do gênero é a presença de uma a poucas células parenquimáticas externas à mestoma $\mathrm{e}$ adjacentes ao tecido xilemático, principalmente aos elementos do metaxilema (Bruhl \& Perry 1995; Soros \& Bruhl 2000; Soros \& Dengler 2001). Diante disso, ainda não tinha sido observado em espécies de Cyperus com via $\mathrm{C}_{4}$, uma terceira bainha com tantas células parenquimáticas externamente à bainha mestoma, e estas localizadas, principalmente adjacentes ao floema.

Além das características anatômicas, os aspectos ultra-estruturais observados em C. maritimus reforçam a indicação da presença da fotossíntese $\mathrm{C}_{4}$ nesta espécie, como, a presença de uma maior quantidade de organelas, principalmente de cloroplastos na bainha do feixe (Carolin et al. 1977; Ueno et al. 1988; Sage 2004). Nas espécies $C_{4}$, os cloroplastos da bainha do feixe, em geral, não apresentam grana desenvolvidos em comparação com as células do mesofilo (Ueno et al. 1988; Marinho \& Estelita 1996). Em C. maritimus, a presença de grana apenas nos cloroplastos do parênquima radiado corrobora o relatado para outras espécies do gênero, como C. bowmanii, C. conicus, C. victoriensis (Carolin et al. 1977), C. corymbosus, C. flavus, C. obtusatus, C. roduntus, C. papyrus (Estelita-Teixeira \& Handro 1987), C. iria (Carolin et al. 1977; Ueno et al. 1988), C. distans, C. nipponicus, C. pilosos (Ueno et al. 1988), C. esculentus (Estelita-Teixeira \& Handro 1987; Estelita 1992) e C. giganteus (Rodrigues \& Estelita 2003).

De acordo com Carolin et al. (1977) a presença de tilacóides convolutos na bainha Kranz, como observado na espécie em estudo, aumenta a área de interface tilacóide-estroma. Este aspecto foi também observado em outras espécies com o tipo clorociperóide, como em Kyllinga brevifolia e Pycreus polystachyos (Carolin et al. 1977; Bruhl \& Perry 1995), Cyperus esculentus (Estelita 1992) e Cyperus giganteus (Rodrigues \& Estelita 2003). Esse caráter é citado como comum em espécies com tipo clorociperóide e fimbristilóide (Estelita-Teixeira \& Handro 1987; Ueno et al. 1988). Entretanto, em Remirea maritima que também apresenta o tipo clorociperóide, Estelita (1992) comenta que os tilacóides dos cloroplastos da bainha Kranz não são convolutos. Diante do exposto, os tilacóides fortemente convolutos observados em $C$. maritimus podem aumentar a eficiência fotossintética nessa espécie.

Carolin et al. (1977), Estelita (1992) e Rodrigues \& Estelita (2003), estudando os aspectos anatômicos e ultra-estruturais de Cyperaceae comentam que não observaram plasmodesmos entre as células da bainha Kranz e as do tecido vascular. Já Ueno et al. (1988) comenta que a presença de plasmodesmos entre as células Kranz e o tecido vascular de Rhynchospora rubra é rara. Nesse contexto, a observação de plasmodemos entre as entre as células da bainha Kranz e o parênquima vascular em $C$. maritimus corresponde a primeira citação dessa característica para o gênero Cyperus.

Assim como em C. maritimus, a ocorrência da lamela de suberina na bainha mestoma é comum em 
plantas $\mathrm{C}_{4}$ de Cyperaceae, sendo sua principal função bloquear a saída apoplástica do $\mathrm{CO}_{2}$, aumentando a concentração na bainha Kranz e conseqüentemente a produção de açúcares (Laetsch 1974; Ueno et al. 1988; Sage 2004). Na bainha mestoma, os plasmodesmos são restritos aos campos de pontoação, onde a lamela de suberina apresenta um aspecto polilamelado (Ueno et al. 1988), como aqui observado. Segundo Crookston (1980), a lamela de suberina pode ser relacionada, quanto a sua morfologia e fisiologia, às estrias de Caspary, o que leva autores a tratá-la de bainha endodemóide (Brown 1975) ou endoderme (Menezes et al. 2003). No presente trabalho a denominação bainha mestoma segue o empregado em trabalhos anatômicas e ultra-estruturais de Cyperaceae (Metcalfe 1971; Estelita-Teixeira \& Handro 1987; Bruhl 1995; Goetghebeur 1998), sendo relacionada à bainha formada por células de parede muito espessa, localizadas entre a bainha parenquimática ou o mesofilo e os vasos (Brown 1975). Além disso, Soros \& Dengler (2001) e Rodrigues \& Estelita (2003) indicam a origem procambial da bainha mestoma.

Cloroplastos ocorrentes no tecido vascular de espécies $\mathrm{C}_{4}$ em Cyperaceae, como o observado em $C$. maritimus, foi também apresentado por Ueno et al. (1988) em Rhynchospora rubra. Crookston \& Ozbun (1975) registraram a ocorrência de cloroplastos no tecido vascular de Boerhavia paniculata (Nyctaginaceae) e Portulaca oleracea (Portulacaceae), sugerindo que estas organelas atuariam na reciclagem do $\mathrm{CO}_{2}$ metabolizado.

Entre os aspectos ultra-estruturais considerados importantes para observação dos danos sofridos por plantas submetidas a estresse salino estão os relacionados a estrutura dos cloroplastos (Flowers et al. 1985; Dekov et al. 2000; Sam et al. 2003), pois um dos principais efeitos do excesso de $\mathrm{NaCl}$ é a perda do envelope e a desorganização do grana nos cloroplastos (Flowers et al. 1985). Os cloroplastos observados em $C$. maritimus não apresentam modificações quanto ao envelope e a estrutura do grana, indicando que estes não são afetados pela condição salina à que a espécie está submetida e que a mesma deve apresentar estratégias que minimizem os danos causados por tal estresse.

Os plastoglóbulos são partículas de lipoprotéina localizadas dentro dos cloroplastos, sendo também indicados como relacionados à condições ambientais (Austin et al. 2006). O incremento no número de plastoglóbulos é relacionado com o aumento do estresse oxidativo no aparato fotossintético e também durante a senescência (Austin et al. 2006). E entre os fatores que atuam nesse estresse oxidativo estão as altas concentrações salinas (Morales et al. 1998; Sam et al. 2003) e o estresse hídrico (Dekov et al. 2000; MunnéBosch \& Alegre 2004). De acordo com Austin et al. (2006), os plastoglóbulos tem como função a biossíntese de corpos lipídicos e são subcompartimentos de armazenamento dos tilacóides, contendo substâncias como carotenóides, plastoquinonas e tocoferol (vitamina E) que atuam na proteção do aparato fotossintético contra os radiais livres. Com isso, a presença desses glóbulos de lipoproteínas, que foram observados principalmente nos cloroplastos do parênquima radiado de $C$. maritimus, pode representar um mecanismo utilizado por esta espécie para evitar possíveis danos ao aparato fotossintético.

Assim como C. maritimus, muitas outras espécies $\mathrm{C}_{4}$ são freqüentemente encontradas em ambientes salinos (Mooney et al. 1991; Rozema 1991), sendo um dos motivos de tal presença relacionado com o uso mais eficiente de água por parte dessas plantas. De acordo com Sage (2004), a eficiência no uso de água e dos nutrientes confere às plantas $\mathrm{C}_{4}$, a capacidade de ocupar habitats que podem ser adversos às $\mathrm{C}_{3}$, como é o caso de ambientes salinos. Essa vantagem está relacionada ao fato do metabolismo $\mathrm{C}_{4}$ ser menos dependente de altas concentrações de $\mathrm{CO}_{2}$, com isso, as plantas com essa via podem reduzir a abertura dos estômatos sem grandes perdas metabólicas, e portanto, diminuir as taxas de evaporação (Sage 2004). Ainda segundo este autor, a aridez e a salinidade foram condições importantes na evolução de plantas com via $\mathrm{C}_{4}$, por efetarem diretamente o fechamento estomático, reduzindo a captação de $\mathrm{CO}_{2}$ e aumentando a fotorrespiração que dificultam a síntese de carboidratos necessária para o crescimento dos vegetais.

Outro aspecto destacado diante do domínio de espécies $\mathrm{C}_{4}$ nesses ambientes é quanto ao requerimento de sódio por parte das plantas com essa via. O sódio é normalmente tóxico para os vegetais, porém estimula o crescimento de plantas com via $\mathrm{C}_{4}$ (Brownell \& Crossland 1972), sendo indicado como fundamental para a entrada de piruvato nas células do mesofilo (parênquima radiado), onde ele atua na regeneração do fosfoenolpiruvato (PEP) que é o substrato da enzima PEPCase (fosfoenolpiruvato carboxilase), que por sua vez, atua na primeira etapa da via $\mathrm{C}_{4}$, a fixação do carbono (Taiz \& Zeiger 2004).

Desse modo, a presença da via fotossintética $\mathrm{C}_{4}$ em C. maritimus atuaria como um mecanismo para compensar a baixa disponibilidade hídrica, o estresse 
salino e a elevada radiação a que essa espécie está submetida, além de ser favorecida pela maior disponibilidade de sódio neste ambiente.

O parênquima aquíffero é também considerado um caráter importante para plantas submetidas a condição salina (Fahn \& Cutler 1992; Degano 1999). Já que as folhas de halófitas tendem a acumular $\mathrm{NaCl}$ por ajuste osmótico, aumentando a suculência do órgão (Flowers \& Yeo 1986). A presença de tecidos responsáveis pelo armazenamento de água é também referida como adaptação para resistência à seca, sendo comum entre as plantas submetidas a estresse hídrico (Fahn \& Cutler 1992). Diante disso, é possível que as camadas de parênquima aqüífero encontradas em $C$. maritimus atuem tanto na osmorregulação quanto na resistência à deficiência hídrica.

As células buliformes são tratadas como de origem epidérmica, porém Metcalfe (1971) sugere que em algumas espécies de Cyperaceae, as células da camada subepidérmica podem ser maiores e mais infladas do que as da própria epiderme, chamando estas também de buliformes. No presente trabalho, apesar da semelhança estrutural das células da camada subepidérmica com as células buliformes, preferimos tratar esta camada como "células parenquimáticas com aspecto buliforme", por não ter sido comprovada a origem destas células.

A presença de vários aspectos estruturais e ultraestruturais relacionados à estratégias que visam minimizar as consequências do estresse hídrico e salino como: parede das células epidérmicas espessa, depósitos de cera, corpos de sílica, parênquima aqüífero desenvolvido e estruturas relacionadas à síndrome Kranz, constituem característícas indicativas de adaptações foliares peculiares em $C$. maritimus associadas à resistência ao ambiente de dunas litorâneas.

\section{Agradecimentos}

Aos técnicos Nivalde Antonio Basso e Maria Helena Moreno do Centro de Microscopia EletrônicaUNESP/Botucatu, pelo auxílio nas técnicas de microscopia eletrônica; aos membros do Laboratório de Morfo-taxonomia Vegetal, pela constante colaboração no desenvolvimento do trabalho; ao CNPq, pela Bolsa de Produtividade em Pesquisa a S.R. Machado; à FAPESP, pelo auxílio financeiro (proc. 00/12469-3).

\section{Referências bibliográficas}

Alvarez, J.M.; Rocha, J.F. \& Machado, S.R. 2005. Estrutura foliar de Loudetiopsis chrysothrix (Nees) Conert e Tristachya leiostachya Nees (Poaceae). Revista Brasileira de Botânica 28: 23-37.

Ashraf , M. \& O'Leary, J.W. 1997. Ion distribution in leaves of salt-tolerant and salt-sensitive lines of spring wheat salt stress. Acta Botanica Neerlandica 46: 207-217.

Austin, J.R.; Frost, E.; Vidi, P.A.; Kessler, F. \& Staehelin, L.A. Plastoglobules are lipoprotein subcompartments of the chloroplast that are permanently coupled to thylakoid membranes and contains biosynthetic enzymes. The Plant Cell 18: 1693-1703.

Berlyn, G. \& Miksche, J. 1976. Botanical microtechnique and cytochemistry. Ames, The Iowa State University Press.

Brown, W.V. 1975. Variations in anatomy, associations and origins of Kranz tissue. American Journal of Botany 62: 395-402.

Brownell, P.F. \& Crossland, C.J. 1972. The requirement for sodium as a micronutrient by species having the dicarboxylic photosynthetic pathway. Plant Physiology 49: 794-797.

Bruhl, J.J. 1995. Sedge genera of the world: relationships and new classification of the Cyperaceae. Australian Systematic Botany 8: 125-305.

Bruhl, J.J. \& Perry, S. 1995. Photosynthetic pathway-related ultrastructure of $\mathrm{C}_{3}, \mathrm{C}_{4}$ and $\mathrm{C}_{3}$-like $\mathrm{C}_{3}-\mathrm{C}_{4}$ intermidiate sedges (Cyperaceae), with special reference to Eleocharis. Australian Journal of Plant Physiology 22: 521-530.

Carolin, R.C.; Jacobs, W.L. \& Vesk, M. 1977. The ultrastructure of Kranz cells in the family Cyperaceae. Botanical Gazette 138: 413-419.

Chaves, M.M. \& Oliveira, M.M. 2004. Mechanisms underlying plant resilience to water deficits: prospect for water-saving agriculture. Journal of Experimental Botany 55: 2365-2384.

Cheplick, G.P. \& White, T.P. 2002. Saltwater spray as an agent of natural selection: no evidence of local adaptation within a coastal population of Triplasis purpurea (Poaceae). American Journal of Botany 89: 623-631.

Cordazzo, C.V. \& Seelinger, U. 2003. Reproduction and vegetative regeneration in Blutaparon portulacoides (Amaranthaceae) on backshores of southern Brazil. Journal of Coastal Research 35: 481-485.

Cordeiro, S.Z. 2005. Composição e distribuição da vegetação herbácea em três áreas com fisionomias distintas na Praia do Peró, Cabo Frio, RJ, Brasil. Acta Botanica Brasilica 19: 679-693.

Crookston, R.K. 1980. The structure and function of $\mathrm{C}_{4}$ vascular tissue. Berichte der Deutschen Botanischen Gesellschaft 93: 71-78.

Crookston, R.K. \& Ozbun, J.L. 1975. Occurrence and ultrastructure of chloroplasts in phloem parenchyma of leaves of C4 dicotyledons. Planta 123: 247-255. 
Degano, C.A.M. 1999. Respuestas morfológicas y anatómicas de Tessaria absinthioides (Hook. Et Arn.) DC. a la salinidad. Revista Brasileira de Botânica 22: 357-363.

Dekov, I.; Tsonev, T.; Yordanov, I. 2000. Effects of water stress and high-temperature stress on the structure and activity of photosynthetic apparatus of Zea mays and Helianthus annuus. Photosynthetica 38: 361-366.

Estelita, M.E.M. 1992. Origin and structure of the Kranz tissues in Cyperaceae. Boletim de Botânica da Universidade de São Paulo 13: 41-48.

Estelita, M.E.M. 1993. Anatomia dos órgãos vegetativos de Remirea maritima Aubl. (Cyperaceae). Naturalia 18: 123-134.

Estelita-Teixeira, M.E.M. \& Handro, W. 1987. Kranz pattern in leaf, scape and bract of Cyperus and Fimbristylis species. Revista Brasileira de Botânica 10: 105-111.

Fahn, A. \& Cutler, D.F. 1992. Xerophytes. Berlin, Gebrüder Borntraeger.

FEEMA 1988. Fundação Estadual de Engenharia do Meio Ambiente. Importância da biota da região de Cabo Frio. Rio de Janeiro, FEEMA.

Flowers, T.J.; Troke, P.F. \& Yeo, A.R. 1977. The mechanism of salt tolerance in halophytes. Annual Review of Plant Physiology 28: 89-121.

Flowers, T.J.; Duque, E.; Hajibagheri, M.A.; McGonogle, T.P. \& Yeo, A.R. 1985. The effect of salinity on leaf ultrastructure and net photosynthesis in two varieties of rice: further evidence for a cellular component of saltresistance. New Phytologist 100: 37-43.

Flowers, T.J. \& Yeo, A.R. 1986. Ion relations of plants under drought and salinity. Australian Journal of Plant Physiology 13: 75-91.

Ghouse, A.K.M. \& Yunus, M. 1972. Preparations of epidermal peels from leaves of Gymnosperm by treatment with 60\% HNO3. Stain Technology 47: 322-325.

Goetghebeur, P. 1998. Cyperaceae. Pp. 141-190. In: K. Kubitzki; H. Huber; P.J. Rudall; P.S. Stevens \& T. Stützel (eds.). The families and genera of vascular plants. Berlin, Springer-Verlag.

Hasegawa, P.M. \& Bressan, R.A. 2000. Plant cellular e molecular responses to high salinity. Annual Review of Plant Physiology and Plant Molecular Biology 51: 463-499.

Hu, Y.; Fromm, J. \& Schmidhalter, U. 2005. Effect of salinily on tissue architecture in expanding wheat leaves. Planta 220: 838-848.

Ihlenfeldt, H.D. \& Hartmann, H.E.K. 1982. Leaf sufarces in Mesembryanthemaceae. Pp. 397-423. In: D.F. Cutler; K.L. Alvin \& C.E. Price (eds.). The plant cutilcle. London, Academic Press.

Johansen, D. 1940. Plant microtechnique. New York, McGraw-Hill Book Inc.

Jordaan, A. \& Kruger, H. 1992. Leaf surface and anatomy of two xerophtic plants from southern Africa. South African Journal of Botany 58: 133-138.

Kraus, J. \& Arduin, M. 1997. Manual básico de métodos em morfologia vegetal. Rio de Janeiro, EDUR.
Laetsch, W.M. 1974. The $\mathrm{C}_{4}$ syndrome: a structural analysis. Annual Review of Plant Physiology 25: 27-52.

Levering, A.C. \& Thomson, W.W. 1971. The ultrastructure of salt glands of Spartina foliosa. Planta 97: 183-196.

Luceño, M.; Alves, M. \& Mendes, A.P. 1997. Catálogo florístico y claves de identificación de las ciperáceas de los Estados de Paraíba y Pernambuco (Nordeste de Brasil). Anales del Jardín Botânico de Madrid 55: 67-100.

Marinho, T.C. \& Estelita, M.E.M. 1996. Anatomia e ultraestrutura foliar das Portulacaceae da Serra do Cipó, Minas Gerais. Revista Brasileira de Botânica 19: 61-65.

Marcum, B. \& Murdoch, C.L. 1992. Salt tolerance of the coastal salt marsh grass, Sporobolus virginicus (L.) Kunth. New Phytologist 120: 281-288.

Matias, L.Q. \& Nunes, E.P. 2001. Levantamento florístico da área de proteção ambiental de Jericoacara, Ceará. Acta Botanica Brasilica 15: 33-43.

Maun, M.A. 1994. Adaptations enhancing survival and establishment of seedlings on coastal dune systems. Vegetatio 111: 59-70.

Menezes, N.L.; Silva, D.C. \& Melo-de-Pinna, G.F.A. 2003. Folha. Pp. 303-325. In: B. Appezzato-da-Glória \& S. Carmello-Guerreiro (eds.). Anatomia Vegetal. Viçosa, Editora UFV.

Metcalfe, C.R. 1971. Anatomy of the monocotyledons: Cyperaceae. Oxford, Clarendon Press.

Mooney, H.A.; Winner, W.E. \& Pell, E.J. 1991. Response of plants to multiple stresses. St Louis, Missouri, Academic Press.

Morales, M.A.; Sanchez-Blanco, M.J.; Olmos, E.; Torrecillas, A. \& Alarcon, J.J. 1998. Changes in the growth, leaf water relations and cell ultrastructure in Argyranthemum coronopifolium plants under saline conditions. Journal of Plant Physiology 153: 174-180.

Munné-Bosch, S. \& Alegre, L. 2004. Die and let live: Leaf senescence contributes to plant survival under drought stress. Functional of Plant Biology 31: 203-216.

Naidoo, G.; Mckee, K.L. \& Mendelssohn, I.A. 1992. Anatomical and metabolic responses to waterlogging and salinity in Spartina alterniflora and $S$. patens (Poaceae). American Journal of Botany 79: 765-770.

Oliveira, V.C. \& Sajo, M.G. 1999. Anatomia foliar de espécies epífitas de Orchidaceae. Revista Brasileira de Botânica 22: 365-374.

Oteng-Yeboah, A.A. 1975. Morphology, anatomy and taxonomy of the genus Remirea Aublet (Cyperaceae). Boissiera 24: 197-205.

Perazzolo, M. \& Pinheiro, F. 1991. Aspectos anatômicos e adaptativos das partes vegetativas de Spartina densiflora Brong. (Gramineae) da Marisma do estuário da Lagoa dos Patos-RS. Acta Botanica Brasilica 5: 3-16.

Prichid, C.J.; Rudall, P.J. \& Gregory, M. 2004. Systematic and Biology Bodies in Monocotyledons. The Botanical Review 69: 377-440.

Prisco, J.T. 1980. Alguns aspectos da fisiologia do stress salino. Revista Brasileira de Botânica 3: 85-97.

Purvis, M.; Collier, D. \& Wall, D. 1964. Laboratory Techniques in Botany. London, Butterworths. 
Rodrigues, A.C. \& Estelita, M.E.M. 2003. Origin and structure of the Kranz tissue in bracts of Cyperus giganteus Vahl (Cyperaceae). Revista Brasileira de Botânica 26: 445-452.

Rozema, J. 1991. Growth, water and ion relationships of halophytic monocotyledonae and dicotyledonae; a unified concept. Aquatic Botany 39: 17-33.

Sage, R. 2004. The evolution of $\mathrm{C}_{4}$ photosynthesis. New Phytologist 161: 341-370.

Salatino, A.; Montenegro, G. \& Salatino, M.L. 1986. Microscopia eletrônica de varredura de superfícies foliares de espécies lenhosas do cerrado. Revista Brasileira de Botânica 9: 117-124.

Sam, O.; Ramírez, C.; Coronado, M.J.; Testillano, P.S. \& Risueño, M.C. 2003. Changes in tomato leaves induced by $\mathrm{NaCl}$ stress: Leaf organization and cell ultrastructure. Biologia Plantarum 47: 361-366.

Sass, J. 1951. Botanical Microtechnique. Ames, The Iowa State College Press.

Shannon, M.C. 1997. Adaptation of plants to salinity. Advances in Agronomy 60: 75-120.
Soros, C.L. \& Bruhl, J.J. 2000. Multiple evolucionary origins of $\mathrm{C}_{4}$ photosynthesis in the Cyperaceae. Pp. 629-636. In: K.L. Wilson \& D.A. Morrison (eds.). Monocots: Systematics and Evolution. Melbourne, CSIRO.

Soros, C.L. \& Dengler, N.G. 2001. Ontogenetic derivation and cell differentiation in photosynthetic tissue of $\mathrm{C}_{3}$ and $\mathrm{C}_{4}$ Cyperacae. American Journal of Botany 88: 992-1005.

Taiz, L. \& Zeiger, E. 2004. Fisiologia Vegetal. Porto Alegre, Artmed.

Ueno, O.; Takeda, T. \& Maeda, E. 1988. Leaf ultrastructure of $\mathrm{C}_{4}$ species possessing different kranz anatomical types in the Cyperaceae. The Botanical Maganize of Tokyo 101: 141-152.

Väre, H. \& Kukkonen, I. 2005. Seven new species of Cyperus (Cyperaceae) section Arenarii and one new combination and typification. Annales Botanici Fennici 42: 473-483.

Yeo, A.R. 1983. Salinity resistance: physiologies and prices. Physiologia Plantarum 58: 214-222. 